\title{
An unusual complex mullerian anomaly: case report
}

\section{Anshika Lekhi*, Rahul Manchanda, Sravani Chithra, Nidhi Jain}

Department of Gynae Endoscopy, Manchanda’s Endoscopic Centre, New Delhi, India

Received: 04 May 2016

Accepted: 09 May 2016

*Correspondence:

Dr. Anshika Lekhi,

E-mail: dranshikalekhi@gmail.com

Copyright: (C) the author(s), publisher and licensee Medip Academy. This is an open-access article distributed under the terms of the Creative Commons Attribution Non-Commercial License, which permits unrestricted non-commercial use, distribution, and reproduction in any medium, provided the original work is properly cited.

\section{ABSTRACT}

Congenital anomalies are a result of defect in the normal process of embryonic formation of organs. When more than 1 complete or incomplete defect coexists, they lead to formation of a complex anomaly. Here we report a case of an unusual and unclassified complex uterine anomaly and its management. To the best of our knowledge such a case has not been reported till date in the literature. The authors also reinstate the need for classifying these unusual anomalies.

Keywords: Congenital, Classification, Mullerian duct, Uterine anomalies

\section{INTRODUCTION}

Congenital uterine anomalies result from abnormal formation, fusion or resorption of the Mullerian ducts during fetal life. Complex anomalies are caused due to defect in more than one developmental lines. These are brought into light with complaints of infertility, miscarriage, premature birth, abnormal fetal presentation, cyclic pain, or as incidental diagnosis during pelvic or ultrasonography examination. The prevalence rates of uterine anomalies have varied between $0.06 \%$ and $38 \%$. $^{1-}$

${ }^{8}$ This wide variation is due to the assessment of different patient populations and the use of different diagnostic techniques with variable accuracy rates as well as reliance on non-standardized classification systems. Combined (hysteroscopy/laparoscopy) is considered as the gold standard in diagnosing and treating congenital uterine anomalies. ${ }^{7,8}$ To the best of our knowledge such a case has not been reported till date in the literature, adding to the spectra of complex anomalies.

\section{CASE REPORT}

We present a case of 26 year old woman married for 4 years. She had a history of medical termination of pregnancy 1.5 years back at 6 weeks gestation. She was also a known case of hypothyroidism. She had been trying to conceive for last 1 year. Her fertility work up done was perfectly normal except unicornuate uterus with unilateral spill in hysterosalphingography (Figure 1). Her ultrasound was normal. She was advised combined laparoscopy with hysteroscopy approach. Her hysteroscopy showed a unicornuate cavity with absence of right ostia (Figure 2). But to our surprise, her laparoscopy showed a normal shape and size of the uterus with unilateral deficient cavity. Half of the uterus was solid and half had the cavity (Figure 3). Bilateral ovaries were normal. The right sided fallopian tube was noncanalized (Figure 4). We did a hysteroscopic metroplasty for her to increase the cavity and make it more roomy. This would facilitate her for further planning her family. This case according to the new ESHRE classification comes in class VI of unclassified anomalies.

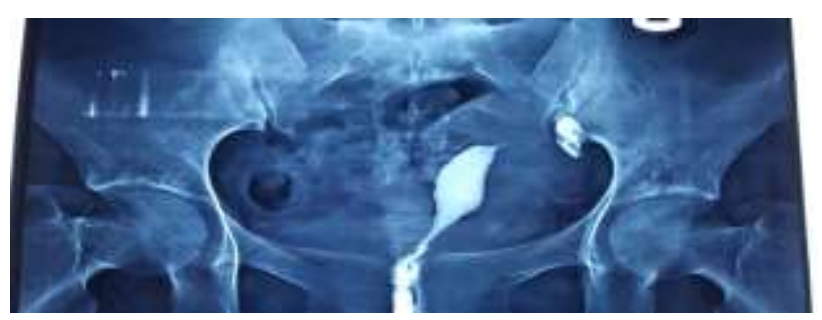

Figure 1: HSG showing unicornuate uterus with unilateral spill. 


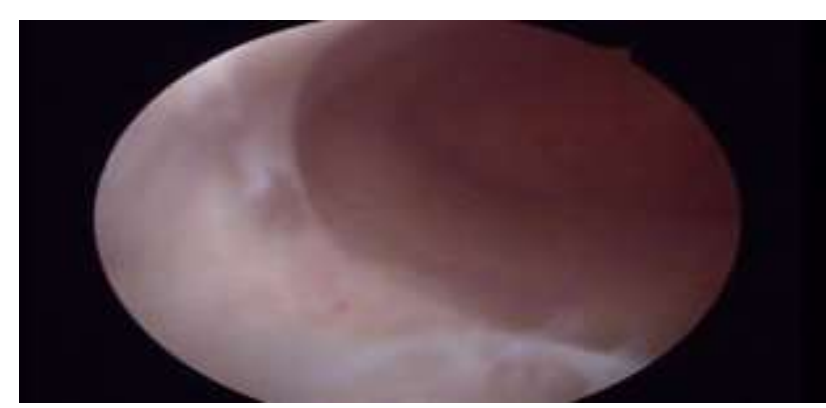

Figure 2: Hysteroscopy showing unicornuate cavity with 1 ostia.

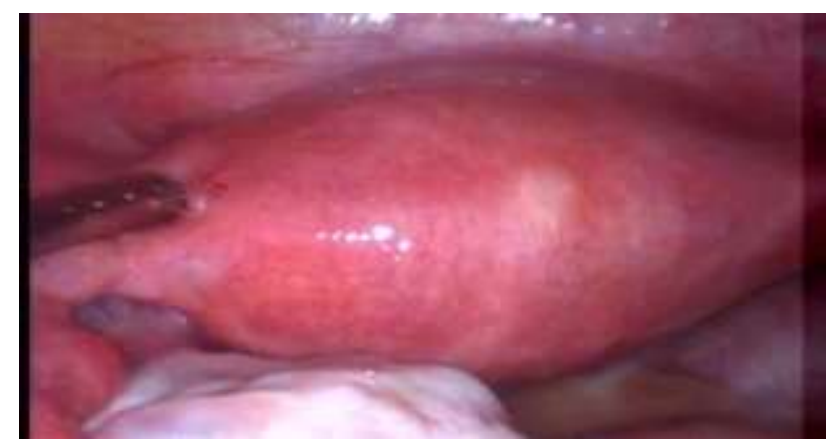

Figure 3: Normal size and shape uterus with hemi cavity.

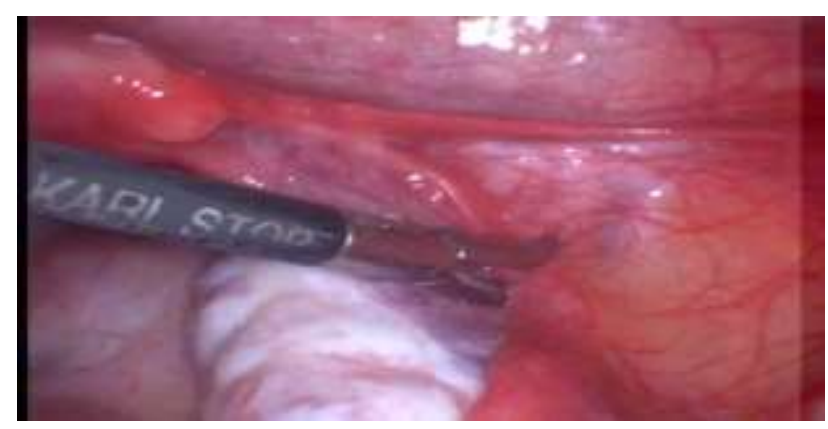

Figure 4: Righted rudimentary tube with normal ovary.

\section{DISCUSSION}

Complex uterine anomalies can occur due to complete or incomplete combination of two mullerian anomalies. These anomalies have been associated with an increased rate of infertility, miscarriage, preterm delivery and other adverse fetal outcomes.

Till now there is no classification which can describe all possible mullerian anomalies. Many classification systems are given to classify Mullerian duct anomalies with variable level of acceptance and For long the American Fertility Society (AFS) currently known as American Society of Reproductive Medicine system (ASRM) classification was the most accepted worldwide, being easy to interpret. ${ }^{9-15}$ Sadly, it also had some fallacies, mainly difficult classification of mixed uterine anomalies, absence of diagnostic parameters for anomalies, complete dependence on subjective impressions of clinician performing the diagnostic test, being noncomprehensive to some rare anomalies and some studies have added objective parameters to this classification to improve it. ${ }^{13-21}$

In 2013, the European Society of Human Reproduction and Embryology (ESHRE) and the European Society for Gynaecological Endoscopy (ESGE) gave a new classification based primarily on anatomy of the female genital tract. Anomalies were classified progressively according to the degree of the anatomical deviation. Coexistent cervical or vaginal anomalies are classified independently. This new classification is expected to be more precise and presentable and would provide the ease in deciding management protocol according to anomaly description. ${ }^{22}$ Somayya M. Sadek et al has compared the performance of the classification sytems also. ${ }^{23}$ Still any of these classification do not classify our anomaly. We would like to name it as a hemi cavity canalization defect. As it had a normal size and shaped uterus with 1 half of the uterine cavity being non cavitated. The fallopian tube also on that side was non-canalized and rudimentary.

\section{CONCLUSION}

Authors stress upon the rarity of this case. There has been no similar case reported in the literature till date, adding to the spectra of complex anomalies. This also emphasizes on the need for classifying the unclassified anomalies.

\section{Funding: No funding sources \\ Conflict of interest: None declared \\ Ethical approval: Not required}

\section{REFERENCES}

1. Simon C, Martinez L, Pardo F, Tortajada M, Pellicer A. Mullerian defects in women with normal reproductive outcome. Fertil Steril. 1991;56:1192-3.

2. Makino T, Hara T, Oka C, Toyoshima K, Sugi T, Iwasaki K, Umeuchi M, Iizuka R. Survey of 1120 Japanese women with a history of recurrent spontaneous abortions. Eur J Obstet Gynecol Reprod Biol. 1992;44(2):123-30.

3. Makino T, Umeuchi M, Nakada K, Nozawa S, Iizuka $\mathrm{R}$. Incidence of congenital uterine anomalies in repeated reproductive wastage and prognosis for pregnancy after metroplasty. Int J Fertil. 1992; 37(3):167-70.

4. Clifford K, Rai R, Watson H, Regan L. An informative protocol for the investigation of recurrent miscarriage: preliminary experience of 500 consecutive cases. Hum Reprod. 1994;9:1328-32.

5. Acien P. Uterine anomalies and recurrent miscarriage. Infertil Reprod Med Clin North Am. 1996;7:689-719. 
6. Homer HA, Li TC, Cooke ID. The septate uterus: a review of management and reproductive outcome. Fertil Steril 2000;73:1-14.

7. Filho HAG, Mattar R, Pires CR, Araujo E Jr, Moron AF, Nardozza LMM. Comparison of hysterosalpingography, hysterosonography and hysteroscopy in evaluation of the uterine cavity in patients with recurrent pregnancy losses. Arch Gynecol Obstet. 2006;274(5):284-8.

8. Filho HAG, Mattar R, Pires CR, Araujo E Jr, Moron AF, Nardozza LMM. Prevalence of uterine defects in habitual abortion patients attended on at a university health service in brazil. Arch Gynecol Obstet. 2006;274:345-8.

9. Acien P, Acien MI. The history of female genital tract malformation classifications and proposal of an updated system. Hum Reprod Update. 2011;17(5):693-705.

10. Buttram VC, Gomel V, Siegler A, DeCherney A, Gibbons W, March C. The american fertility society classifications of adnexal adhesions, distal tubal occlusion, tubal occlusion secondary to tubal ligation, tubal pregnancies, mullerian anomalies and intrauterine adhesions. Fertil Steril. 1988;49:944-55.

11. Oppelt P, Renner SP, Brucker S, Strissel PL, Strick R, Oppelt PG, et al. The VCUAM (Vagina Cervix Uterus Adnexa associated Malformation) classification: a new classification for genital malformations. Fertil Steril. 2005;84(5):1493-7.

12. Salim R, Woelfer B, Backos M, Regan L, Jurkovic D. Reproducibility of three dimensional ultrasound diagnosis of congenital uterine anomalies. Ultrasound Obstet Gynecol. 2003;21(6):578-82.

13. Deutch TD, Abuhamad AZ. The role of 3dimensional ultrasonography and magnetic resonance imaging in the diagnosis of mullerian duct anomalies a review of the literature. J Ultrasound Med. 2008;27(3):413-23.

14. Troiano RN. Magnetic resonance imaging of mullerian duct anomalies of the uterus. Top Magn Reson Imag. 2003;14(4):269-79.
15. Bermejo C, Martinez Ten P, Cantarero R, Diaz D, Pedregosa JP, Barrn E, et al. Three dimensional ultrasound in the diagnosis of mullerian duct anomalies and concordance with magnetic resonance imaging. Ultrasound Obstet Gynecol. 2010;35 (5):593-601.

16. Umobi MA, Meltz RC, Barmat LI. Accessory uterine appendage may be a new mullerian malformation. Fertil Steril. 2005;84(4):1017.

17. Woelfer B, Salim R, Banerjee S, Elson J, Regan L, Jurkovic D. Reproductive outcomes in women with congenital uterine anomalies detected by threedimensional ultrasound screening. Obstet Gynecol. 2001;98(6):1099-103.

18. Brown SJ, Badawy SZ. A rare mullerian duct anomaly not included in the classification system by the american society for reproductive medicine. Case Rep Obstet Gynecol. 2013;2013:569480.

19. Deffarges JV, Haddad B, Musset R, Paniel BJ. Utero-vaginal anastomosis in women with uterine cervix atresia: long-term follow-up and reproductive performance. a study of 18 cases. Hum Reprod. 2001;16(8):1722-5.

20. Pavone ME, King JA, Vlahos N. Septate uterus with cervical duplication and a longitudinal vaginal septum: a mullerian anomaly without a classification. Fertil Steril. 2006;85(2):494. e9-e10.

21. Troiano RN, McCarthy SM. Mullerian duct anomalies: imaging and clinical issues. Radiology. 2004;233(1):19-34.

22. Grimbizis GF, Gordts S, Sardo A, Brucker S, De Angelis C, Gergolet M, et al. The ESHRE/ESGE consensus on the classification of female genital tract congenital anomalies. Hum Reprod. 2013;28(8):2032-44.

23. Sadek SM, Ahmad RA, Atia H. Performance of the ESHRE/ESGE classification. Middle East Fertil Soc J. 2016:75-81.

Cite this article as: Lekhi A, Manchanda R, Chithra $\mathrm{S}$, Jain N. An unusual complex mullerian anomaly: case report. Int J Reprod Contracept Obstet Gynecol 2016;5:2026-8. 